Received Date : 14-Sep-2015

Revised Date : 27-Oct-2015

Accepted Date : 25-Jan-2016

Article type : Research Article

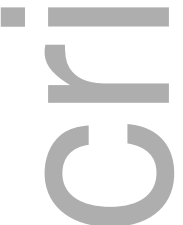

Title: Diabetic Medicine

Created by: Maria Hale

Email proofs to: grance@unimelb.edu.au

Copyright: Diabetes UK

Article no.: DME-2015-00753

Article type: Research Article

Figures: 2; Tables: 2; Equations:0; References: 30

Short title/Authors running head: Hearing in children with Type 1 diabetes $\bullet$ G. Rance et al.
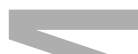

Research: Complications

\title{
Functional hearing deficits in children with Type 1 diabetes
}

G. Rance ${ }^{1}$, D. Chisari ${ }^{1}$, N. Edvall ${ }^{2}$ and F. Cameron ${ }^{3}$

${ }^{1}$ Department of Audiology \& Speech Pathology, The University of Melbourne, Melbourne, Australia,

${ }^{2}$ Department of Audiology, Lund University, Lund, Sweden, and ${ }^{3}$ Department of Endocrinology \& Diabetes, Royal Children's Hospital, Parkville, Australia

This is the author manuscript accepted for publication and has undergone full peer review but has not been through the copyediting, typesetting, pagination and proofreading process, which may lead to differences between this version and the Version of Record. Please cite this article as doi: $10.1111 / \mathrm{dme} .13086$

This article is protected by copyright. All rights reserved 


\section{What's new?}

- This study explores functional hearing deficits in children with Type 1 diabetes. As such, it differs from most work in this field, which has only considered the effect of diabetes on sound detection ability.

- We demonstrate auditory pathway disorder in individuals with normal sound detection thresholds and consider the underlying mechanisms.

- The findings highlight binaural processing deficits and their effect on speech processing in background noise.

- Everyday listening ability is considered, as are potential developmental risks.

Correspondence to: Gary Rance. Email: grance@unimelb.edu.au

\section{Abstract}

Aim Hearing loss (as reflected by abnormal sound detection) is a frequently reported consequence of Type 1 diabetes mellitus. We sought to evaluate sound detection, auditory neural function and binaural processing ability in a group of school-aged participants with Type 1 diabetes and to assess their functional hearing and general communication ability. Methods A range of electroacoustic, electrophysiological and behavioural test techniques were used to evaluate both cochlear and auditory neural function in 19 affected children. A cohort of matched controls was also assessed.

Results Although all of the participants with Type 1 diabetes enjoyed normal sound detection, 9 of the 19 (47\%) showed evidence of auditory pathway abnormality with evoked potential latencies and/or amplitudes beyond age-related norms. Auditory brainstem response interpeak latencies (wave I-V) were longer than in matched controls [ $95 \%$ confidence interval (95\% CI); 0.10, $0.28 \mathrm{~ms}: P<0.001]$ and wave V amplitudes were reduced (95\% CI; $-0.21,0.00 \mu \mathrm{V}: P=0.02)$. Binaural speech perception in noise was also impaired $(95 \% \mathrm{CI}$; $0.82,3.17 \mathrm{~dB}: P=0.002$ ) and perceptual ability was correlated with degree of neural disruption in the auditory brainstem $(r=0.662, P=0.003)$.

Conclusions Hearing deficits severe enough to restrict communication and threaten academic progress were common on our group of school-aged children with Type 1 diabetes.

Evaluation of both cochlear and auditory neural function may form an important part of the standard management regime for children with diabetes. 


\section{Introduction}

Diabetic peripheral neuropathy is one of the major clinical consequences of Type 1 diabetes mellitus. The prevalence of neuropathy in affected individuals is $~ 30 \%$ with up to $50 \%$ showing clinically significant neural injury during the disease course [1,2]. Diabetes can damage the peripheral nervous system in various ways, but the most common presentation is a distal symmetric polyneuropathy. Other patterns of injury include small-fibre predominant neuropathy, radiculoplexopathy and autonomic neuropathy [3]. Both the motor and sensory peripheral nervous systems can be impacted, and in the case of the latter, abnormality in the somatosensory and visual modalities is common [3,4].

Hearing loss (as reflected by abnormal sound detection thresholds) has also been reported in a high proportion (10-80\%) of adults $[5,6]$ and children $[7,8]$ with Type 1 diabetes. The mechanisms underlying auditory deficit are variable and can involve both cochlear and retrocochlear dysfunction. The main proposed causes are interference of nutrient transportation through thickened capillary walls, flow reductions due to narrowed vessels and secondary degeneration of the vestibulo-cochlear nerve causing neuropathy [9]. The presence of auditory neuropathy in diabetes has been indicated in both electroacoustic studies showing a lack of contralateral suppression of otoacoustic emissions (suggesting disruption of the olivocochlear efferent system) [10] and in electrophysiological investigations, which have revealed slowing of neural conduction in the auditory nerve and brainstem [6,11-13]. Furthermore, histological studies have exhibited a range of neural abnormalities including VIIIth nerve demyelination and spiral ganglion cell loss [14,15].

It is now well established in other neuropathic conditions involving the peripheral nerves (Friedreich ataxia, Charcot-Marie-Tooth disease and others) that auditory neuropathy, by affecting the integrity of neural transmission in the central auditory pathways, can produce significant perceptual deficits [16-19]. In particular, the representation of timing cues in the acoustic signal may be disrupted, leading to a loss of temporal resolution and impaired discrimination of speech information based on timing differences such as vowel duration or consonant voice onset times [17]. In a previous study, we demonstrated auditory processing deficits in adult participants with auditory neuropathy and Type 1 diabetes [20]. In this experiment, we explore the perceptual, everyday listening and communication consequences of auditory neuropathy in school-aged children with Type 1 diabetes.

\section{Methods}

This article is protected by copyright. All rights reserved 
Nineteen children (seven female) with Type 1 diabetes were recruited through the Diabetes Complications Clinic at the Royal Children's Hospital, Melbourne. Thirty-two cases were seen in clinic over the period of study, which represents a $59.4 \%$ participation rate. Each participant was well at the time of assessment and was attending a routine outpatient appointment. All had been evaluated by experienced endocrinologists and had begun an insulin regimen involving either multiple daily injections $(N=10)$ or an insulin pump $(N=9)$ within 2 months of initial diagnosis. Participant details are shown in Table 1 . $\mathrm{HbA}_{1 \mathrm{c}}$ levels ranged from 47 to $84 \mathrm{mmol} / \mathrm{mol}$ (6.5 to $9.8 \%)$. Age at disease onset ranged from 0.5 to 15.5 years and disease duration ranged from 1.2 to 13.2 years. Participants underwent measures of visual acuity within one month of hearing assessment.

Nineteen age- and gender-matched control participants were also recruited. Each participant's guardian reported that their child was diabetes free, although this was not confirmed with by measurement of blood glucose or $\mathrm{HbA}_{1 \mathrm{c}}$ level. Mean age at assessment for the Type 1 diabetes group was 13.4 (2.8) years and for the control cohort was 13.5 (3.0) years. For each case/control pair the age-match was within 12 months.

The research protocol was approved by the Ethics Committee of the Royal Victorian Eye and Ear Hospital and written informed consent was obtained for each participant. All testing was carried according to Declaration of Helsinki (2000) guidelines. Each child underwent a battery of auditory tests in a single session lasting $\sim 60 \mathrm{~min}$.

\section{Cochlear function}

\section{Sound detection thresholds}

Each participant undertook audiometric assessment in a quiet room where background noise levels were < $40 \mathrm{dBA}$. Sound detection thresholds were established at octave frequencies across the audiometric range $(250 \mathrm{~Hz}$ to $8 \mathrm{kHz})$. A four-frequency average based on hearing thresholds at 500,1000, 2000 and $4000 \mathrm{~Hz}$ was calculated for each ear.

\section{Otoacoustic emissions}

Distortion product otoacoustic emission (DPOAE) assessment was performed bilaterally. Stimulus tones presented in pairs with a frequency ratio $\left[\mathrm{f}_{2} / \mathrm{f}_{1}\right]$ of 1.22 were used to elicit the emission. These signals ranged in frequency from 902 to $2566 \mathrm{~Hz}$, and were presented at $55 \mathrm{dBSPL}\left(\mathrm{f}_{2}\right)$ and $65 \mathrm{dBSPL}\left(\mathrm{f}_{1}\right)$. Average DPOAE amplitude $(\mathrm{dB})$ was calculated for each ear based on response level at four test frequencies.

This article is protected by copyright. All rights reserved 


\section{Auditory electrophysiology}

Auditory brainstem responses (ABRs) were recorded to acoustic click stimuli presented at a rate of $33 \mathrm{~Hz}$ to each ear individually at $90 \mathrm{dBnHL}$. Electroencephalographic samples following 2000 clicks were averaged to produce each test run. A minimum of two runs was obtained in each stimulus condition and compared to determine waveform repeatability. Post hoc analysis of the recordings was carried out independently by two experienced clinicians blinded to participant identity. These judges determined the post-stimulus latency of ABR waves I, III and V, and the peak-to-peak amplitude of wave V.

\section{Functional hearing}

Binaural speech perception assessment was undertaken using the Listening in Spatialized Noise (LiSN-S) test, which measures the listener's ability to segregate a target speech signal from a competing speech noise [21]. The test is administered under headphones, but a threedimensional auditory environment is created by synthesizing the stimuli with a head-related transfer function. Speech reception threshold, the signal-to-noise ratio required for the listener to identify $50 \%$ of the words in target sentences, is established in four conditions, which vary in terms of the location of the noise source $\left(0^{\circ}\right.$ vs. $90^{\circ}$ azimuth). An 'advantage' measure representing the $\mathrm{dB}$ benefit afforded by the spatial separation of target and noise sources is also calculated.

\section{Hearing/communication disability questionnaire}

Everyday listening and general communication ability was investigated using a hearing disability survey [the Abbreviated Profile of Hearing Aid Benefit (APHAB)] completed by each participant. Children $\leq 10$ years were assisted by a parent. This 24 -question metric explores four aspects of auditory function: communication difficulty, the effect of background noise, the effect of reverberation and aversion to loud sounds. A 'global score' derived from the communication, noise and reverberation subscales was calculated for each child.

\section{Results}

\section{Sound detection thresholds}

This article is protected by copyright. All rights reserved 
Sound detection in children with Type 1 diabetes was mildly elevated (poorer) relative to that of matched controls (Fig. 1A). Children in both groups showed relatively poor detection thresholds at the $250 \mathrm{~Hz}, 500 \mathrm{~Hz}$ and $1 \mathrm{kHz}$ test frequencies, reflecting the fact that assessment took place in a non-sound-treated room. Ambient noise levels are greatest in the low frequencies and it is likely that low-level stimuli were masked in this range. Paired $t$-testing revealed a significant group difference in mean four-frequency average hearing level [Type 1 diabetes: 10.5 (3.9) dBHL; control: 7.5 (3.0) dBHL, 95\% confidence interval (95\% $\mathrm{CI}) ; 1.3,4.8 \mathrm{~dB}: P<0.001)$. Despite this group difference, none of the participants suffered significantly impaired sound detection, with average hearing levels in each case falling within normal clinical limits ( $\leq 15 \mathrm{dBHL}$ ). Correlation analysis (Pearson $r$ ) found no relation between average hearing level (poorer ear) and age at disease onset, disease duration, $\mathrm{HbA}_{1 \mathrm{c}}$ $(\%)$ level or visual acuity (LogMAR) $(P>0.05)$ in participants with Type 1 diabetes.

\section{Otoacoustic emissions}

Repeatable otoacoustic emissions were obtained bilaterally for each study participant. Average DPOAE response amplitude was, however, significantly lower for the Type 1 diabetes group, indicating that the mechanical processes of the cochlea were affected [Type 1 diabetes: 14.0 (4.1) dB; control: 23.7 (7.2) dB, 95\% CI; -12.3, -7.0 dB: $P<0.001]$ (Fig. 1B). Correlation analysis found no relation between DPOAE amplitude (poorer ear) and age at disease onset, disease duration, $\mathrm{HbA}_{1 \mathrm{c}}$ level or visual acuity $(\log \mathrm{MAR})(P>0.05)$ in the participants with diabetes.

\section{Auditory brainstem response}

Brainstem response waveforms were observed bilaterally for each participant with diabetes. Mean response latencies and amplitudes are shown in Table 2. There was no group difference in ABR wave I latency $(95 \% \mathrm{CI} ;-0.06,0.07 \mathrm{~ms}: P=0.95)$ or wave III latency $(95 \% \mathrm{CI}$; $0.01,0.15 \mathrm{~ms}: P=0.07$ ), but wave $\mathrm{V}$ was significantly delayed in participants with Type 1 diabetes (95\% CI; 0.10, $0.29 \mathrm{~ms}: P<0.001)$. Neural conduction times (interpeak latencies) were also prolonged in children with Type 1 diabetes (Table 2). Mean I-III conduction time (reflecting activity in the VIIIth nerve and up to the level of the cochlear nucleus) was not significantly longer than in controls $(P=0.09)$, but 4 of 19 participants with Type 1 diabetes showed interpeak latencies beyond the normal clinical range (> $2.45 \mathrm{~ms})$ [17,18]. Central brainstem changes were also observed in some children with ABR III-V latency (reflecting 
conduction between cochlear nucleus and inferior colliculus) exceeding the clinical limit $(2.20 \mathrm{~ms})$ in 3 of 19 cases.

Because participant age, gender and sound detection level can affect ABR outcomes, the interpeak latency data were subjected to a multiple regression analysis to look for associations between ABR result and participant group (presence of Type 1 diabetes), age at assessment, gender and four-frequency average hearing level. Interpeak latency (I-III) was not correlated with participant group $(P=0.056)$, age $(P=0.670)$, gender $(0.604)$ or average hearing level $(P=0.745)$. Wave III-V interpeak latency was not correlated with age $(P=0.489)$, gender $(P=0.625)$ or hearing level $(P=0.870)$, but participant group was a significant factor $(P=0.008)$. That is, neural conduction times were significantly longer in children with Type 1 diabetes. Similarly, wave I-V latency showed no relation with age $(P=0.446)$, gender $(P=0.340)$ or hearing level $(P=0.830)$, but the presence of Type 1 diabetes was significant $(P=0.003)$.

Among participants with Type 1 diabetes, correlation analysis showed no relation between wave I-III latency and age at disease onset $(P=0.116)$, disease duration $(P=0.203), \mathrm{HbA}_{1 \mathrm{c}}$ level $(P=0.482)$ or visual acuity (LogMAR) $(P=0.492)$. Wave III-V latency also showed no correlation with disease duration $(P=0.112)$ and $\mathrm{HbA}_{1 \mathrm{c}}(P=0.175)$, but was significantly correlated with age of disease onset $(r=-0.512, P=0.030)$ and $\operatorname{LogMAR}(r=-0.592$, $P=0.020$ ), with those children exhibiting the most delayed neural conduction also those with the earliest disease onset and poorest vision. Wave I-V interpeak latency showed no relation with disease duration $(P=0.479), \mathrm{HbA}_{1 \mathrm{c}}(P=0.401)$ or visual acuity $(P=0.312)$, but was, again, negatively correlated with age of disease onset $(r=-0.482, P=0.042)$.

Brainstem response amplitude was reduced in participants with diabetes. Mean peak-to-peak wave $\mathrm{V}$ amplitude for the Type 1 diabetes group was $0.50(0.19) \mu \mathrm{V}$ and for the control group was $0.62(0.23) \mu \mathrm{V}(95 \% \mathrm{CI} ;-0.21,0.00 \mu \mathrm{V}: P=0.02)$. Multiple regression analysis revealed no significant effect of age $(P=0.675)$, gender $(P=0.064)$ or hearing level $(P=0.155)$, but did show a significant group effect $(P=0.021)$. Among participants with diabetes, there was no correlation between ABR amplitude and age of disease onset $(P=0.210)$, disease duration $(P=0.476), \mathrm{HbA}_{1 \mathrm{c}}(P=0.313)$ or visual acuity $(P=0.587)$.

\section{Binaural speech perception}

Speech reception thresholds were significantly higher (poorer) for children with Type 1 diabetes in listening conditions where binaural difference cues were available, i.e. when the target speech and background noise were presented from different directions [(DV90 $\left.{ }^{\circ}\right)$ This article is protected by copyright. All rights reserved 
Type 1 diabetes: $-14.8(2.0) \mathrm{dB}$; control: $-16.8(1.4) \mathrm{dB}, 95 \% \mathrm{CI}$; 0.82, $3.17 \mathrm{~dB}: P=0.002]$, [(SV90 $\left.{ }^{\circ}\right)$ Type 1 diabetes: -12.9 (2.4) dB; control: -14.6 (2.3) dB, 95\% CI; 0.17, $3.07 \mathrm{~dB}$ : $P=0.03]$. For conditions where no binaural cues were available (i.e. where target and noise were presented from the same direction) mean reception thresholds for the diabetic and control groups were equivalent $\left[\left(\mathrm{DV}^{\circ}\right)\right.$ Type 1 diabetes: $-6.2(2.9) \mathrm{dB}$; control: -7.3 (2.2) dB, 95\% CI; -0.42, $2.58 \mathrm{~dB}: P=0.15]$, [(SV0 $\left.{ }^{\circ}\right)$ Type 1 diabetes: -1.3 (1.9) dB; control: $-1.3(1.1) \mathrm{dB}, 95 \% \mathrm{CI} ;-0.84,0.89 \mathrm{~dB}: P=0.95]$.

Children with Type 1 diabetes were impaired in their ability to use spatial cues to aid discrimination in background noise. Mean speech reception threshold improvement when the target and noise were spatially separated was 11.6 (2.0) $\mathrm{dB}$ for the diabetic cohort, whereas the controls showed an average improvement of $13.3(1.8) \mathrm{dB},(95 \% \mathrm{CI} ;-2.91,-0.39 \mathrm{~dB}$ : $P=0.01)$.

Multiple regression analysis showed no relation between degree of spatial advantage and age at assessment $(P=0.103)$, hearing level $(P=0.381)$ or gender $(P=0.333)$, but participant group $(P=0.022)$ was a significant factor. Among individuals with Type 1 diabetes, there was no correlation between spatial advantage and age of disease onset $(P=0.843)$, disease duration $(P=0.708), \mathrm{HbA}_{1 \mathrm{c}}(P=0.701)$ or visual acuity $(P=0.849)$.

\section{Hearing/communication disability questionnaire}

Participants with diabetes considered that they had more difficulty in everyday listening and communication than controls. Mean APHAB global score for the group with diabetes was $19.3(14.9) \%$ and for the control group was 9.8 (7.7)\% (95\% CI; 0.36, 18.65\%: $P=0.04)$ indicating that the children with diabetes reported difficulties in approximately twice as many real-life listening situations as their healthy peers (Fig. 2).

Multiple regression analysis showed no relation between APHAB global score and participant age $(P=0.736)$, gender $(P=0.459)$ or average hearing level $(P=0.117)$. The presence of Type 1 diabetes was a significant factor $(P=0.042)$. Correlation analysis found no relation between APHAB global score and age at disease onset $(P=0.170)$, disease duration $(P=0.563), \mathrm{HbA}_{1 \mathrm{c}}$ level $(P=0.345)$ or visual acuity $(P=0.113)$.

\section{Discussion}

Children with Type 1 diabetes in this study showed evidence of cochlear-sensory dysfunction and neural abnormality affecting both the auditory nerve and brainstem. 
Significant functional hearing deficits were observed and the extent of the perceptual deficit was correlated with degree of neural disruption, rather than sound detection ability. Cochlear pathology was indicated by a reduction in otoacoustic emission amplitude.

Otoacoustic emission amplitudes are sounds produced by the active processes within the inner ear and are mediated by the function of the outer hair cells [23]. Emission abnormalities have been reported previously in Type 1 diabetes, and are thought to be the result of bloodflow irregularities in the stria vascularis [24].

The auditory evoked potential findings in this study indicated significant prolongation of neural activity and diminution of response amplitude in children with Type 1 diabetes. Four of the 19 participants showed prolonged neural conduction prior to the cochlear nucleus, consistent with peripheral nerve abnormality (auditory neuropathy). In addition, response latency and/or amplitude changes in the central auditory brainstem were observed in six participants reflecting abnormal neural activity between cochlear nucleus and inferior colliculus.

The mechanism(s) underlying auditory pathway abnormality in Type 1 diabetes are yet to be confirmed, but reduced conduction efficiency may be a consequence of demyelination which has been reported previously in the auditory nerves of people with diabetes $[14,15]$. Response amplitude reduction may reflect either neural dyssynchrony (another possible consequence of demyelination) $[16,20]$ or a reduction in the number of neural elements available to contribute to the volume conducted potential $[17,20]$.

Speech perception in background noise was significantly impaired for many of the children with Type 1 diabetes. Functional hearing abnormalities have not been described previously in this population, but figure/ground (listening-in-noise) deficits are a cardinal feature of central auditory pathway disorders in which the neural representation of complex acoustic signals (such as speech) may be distorted [16,17]. In this study, there was a strong positive correlation between ABR conduction efficiency (wave I-V latency) and speech reception threshold (DV90 ${ }^{\circ}$ ), with those children showing the greatest degree of neural disruption also presenting with the most affected speech understanding $(r=0.662 ; P=0.003)$. The observed degree of functional hearing disruption is likely to be developmentally significant. For listening conditions replicating everyday circumstances required signal-tonoise ratios were, on average, $\sim 2 \mathrm{~dB}$ higher in participants with Type 1 diabetes. That is, they suffered a greater masking effect from the competing signal and required that the noise level be considerably lower before they could perceive spoken sentences. A $2 \mathrm{~dB}$ figure/ground deficit has the potential to delay academic progress. The negative impact of This article is protected by copyright. All rights reserved 
classroom noise on children is well established with high levels shown to result in reduced memory, motivation and reading ability [25]. Furthermore, a recent large-scale study from the UK [26] has demonstrated a consistent negative relationship between classroom noise levels and Standardized Assessment Test scores for mathematics, literacy and science in children aged 7-11 years. In particular, this work found that the proportion of children failing to reach the 'required academic standard' increased by $\sim 5 \%$ for every $2 \mathrm{~dB}$ increase in classroom noise level.

Cognitive deficit can affect auditory processing ability [27] and it is well established that children with Type 1 diabetes are at risk of mild cognitive impairment over time [28]. The children in this study did, however, show depressed scores on the 'spatial advantage' metric, which is a difference measure derived from performance across different listening conditions. As a relative measure, the effect of non-auditory factors is minimised [22]. Spatial processing deficit affects the child's ability to use direction cues to focus on a target signal within a competing noise and reflects an inability to effectively combine the (distorted) inputs from the left and right ears. Previous studies have shown impaired spatial listening in listeners with auditory neuropathy due to neurodegenerative disease [29].

The auditory deficits demonstrated in formal speech perception testing were also reflected in self-reported hearing disability ratings. Where control listeners found that they struggled to understand conversational speech in $<10 \%$ of everyday circumstances, children with Type 1 diabetes typically reported difficulties in approximately twice as many situations, indicating particular hardship in noisy or reverberant environments such as classrooms, playgrounds and shopping precincts.

\section{Summary}

The findings in this study indicate that functional hearing difficulties are common in Type 1 diabetes. Participants were not selected based on hearing history, yet more than half (53\%) showed performance levels outside age-related norms on speech perception and/or everyday listening measures. These results suggest that hearing evaluation may form an important part of the standard management regimen for children with the disease. The findings also indicate that while sound detection may be impaired in some cases, standard audiometry is not sufficient in this population because disordered auditory processing may be present in individuals with normal hearing thresholds. Binaural speech perception assessment revealed specific spatial processing deficit which, in itself, is sufficient to impair functional hearing/communication. When combined with the cognitive deficits which are a risk in This article is protected by copyright. All rights reserved 
childhood Type 1 diabetes, these auditory difficulties have the potential to delay academic progress [27,28]. Early detection is important in affected children and a range of intervention options (such as remote-microphone listening systems) are available, and have proven beneficial in ameliorating the real-world listening effects of auditory neuropathy [30].

\section{Funding source}

This study was funded by a Project Grant from the Royal Victorian Eye \& Ear Hospital, Melbourne, Australia.

\section{Competing interests}

None.

\section{Acknowledgements}

We gratefully acknowledge the contribution all of the children and families who participated in this study. Thanks also to the staff of the Diabetes Complications Clinic (Royal Children's Hospital, Melbourne) in particular Ms Thalia O'Brien who assisted with participant recruitment. This study was funded by a Project Grant from the Royal Victorian Eye \& Ear Hospital.

\section{Author contributions}

G.R. conceptualized and designed the study, drafted the initial manuscript and approved the final manuscript as submitted. D.C. was involved in study design, participant recruitment/data collection, reviewed/revised the manuscript and approved the final manuscript as submitted. N.E. coordinated and supervised data collection, critically reviewed the manuscript and approved the final manuscript as submitted. F.C. was involved in study design, participant recruitment/data collection, reviewed/revised the manuscript and approved the final manuscript as submitted. G.R. is the guarantor of this work and, as such, had full access to all the data in the study and takes responsibility for the integrity of the data and the accuracy of the analysis.

\section{References}

This article is protected by copyright. All rights reserved 
1 Maser RE, Steenkiste AR, Dorman JS et al. Epidemiological correlates of diabetic neuropathy. Report from Pittsburgh Epidemiology of Diabetes Complications Study. Diabetes 1989; 38: 1456-1461.

2 Johannsen L, Smith T, Havsager AM et al. Evaluation of patients with symptoms suggestive of chronic polyneuropathy. J Clin Neuromuscul Dis 2001; 3: 47-52.

3 Callaghan BC, Cheng HT, Stables CL, Smith AL, Feldman EL. Diabetic neuropathy: clinical manifestations and current treatments. Lancet Neurol 2012; 11(6): 521-534.

4 Rao BJ, Dlouhy BJ. Diabetic retinopathy. N Engl J Med 2012; 366(13): 1227-1239.

5 Kakarlapudi V, Sawyer R et al. The effect of diabetes on sensorineural hearing loss. Otol Neurotol 2003; 24: 382-386.

6 Pessin AB, Martins RH, Pimenta W, Simoes ACP, Marsiglia A, Amaral AV. Auditory evaluation in patients with Type 1 diabetes. Ann Otol Rhinol Laryngol 2008; 117: $366-370$.

7 Fukuda C, Pereira LD, Albernaz PLM, e Castro AMS, de Lemos M, Gushikem P et al. Hearing in children with Type I diabetes mellitus. J Endocrin Met 2012; 2: 216219.

8 Abd El Dayem SM, Abd El Ghany SM, Beshr AE, Hassan AG, Attaya MS. Assessment of hearing in children with Type 1 diabetes mellitus. J Pediatr Endocr Met 2014; 27: 393-402.

9 Smith TL, Raynor E, Prazma J, Buenting JE, Pillsbury HC. Insulin-dependent diabetic microangiopathy in the inner ear. Laryngoscope 1995; 105: 236-240.

10 Ugur AK, Kemaloglu YK, Ugur MB, Gunduz B, Saridogan C, Yesilkaya E et al. Otoacoustic emissions and effects of contralateral white noise stimulation on transient evoked otoacoustic emissions in diabetic children. Int J Pediat Otorhi 2009; 73: 555559.

11 Parving A, Elberling C, Balle V, Parbo J, Dejgaard A, Parving HH et al. Hearing disorders in patients with insulin-dependent diabetes mellitus. Audiology 1990; 29: $113-121$

12 Niedzielska G, Katska E. ABR disturbances in children with insulin dependent diabetes mellitus. Int J Pediatr Otorhi 1998; 44: 1-4.

13 Lisowska G, Namyslowski G Morawski K, Strojek K. Early identification of hearing impairment in patients with Type 1 diabetes mellitus. Otol Neurotol 2001; 22: 316320.

This article is protected by copyright. All rights reserved 
14 Jorgensen MB. The inner ear in diabetes mellitus. Histological studies. Arch Otolaryngol 1961; 74: 373-381.

15 Makishima K, Tanaka K. Pathological changes of the inner ear and central auditory pathway in diabetics. Ann Otol Rhinol Laryngol 1971; 80:: 218-228.

16 Starr A, Picton TW, Sininger YS, Hood LJ, Berlin CI. Auditory neuropathy. Brain 1996; 119: 741-753.

17 Rance G, Fava R, Baldock H et al. Speech perception ability in individuals with Friedreich ataxia. Brain 2008; 131: 2002-2012.

18 Hall JW. New Handbook of Auditory Evoked Potentials. Boston: Pearson, 2007, p. 632.

19 Rance G, Ryan MM, Bayliss K, Gill K, O’Sullivan C, Whitechurch M. Auditory function in children with Charcot-Marie-Tooth disease. Brain 2012; 135: 14121422.

20 Zeng F-G, Kong Y-Y, Michaelewski HJ, Starr A. Perceptual consequences of disrupted auditory nerve activity. J Neurophysiol 2005; 93: 3050-3063.

21 Rance G, Chisari D, O’Hare F et al. Auditory neuropathy in individuals with Type 1 diabetes. J Neurol 2014; 261: 1531-1536.

22 Cameron S, Dillon H. Development of the listening in spatialized noise-sentences test (LiSN-S). Ear Hear 2007; 28: 196-211.

23 Kemp DT. Stimulated acoustic emissions from within the human auditory system. $J$ Acoust Soc Am 1978; 64: 1386-1391.

24 Botelho CT, da Silva-Carvalho SA, Silva IN. Increased prevalence of early cochlear damage in young patients with Type 1 diabetes detected by distortion product otoacoustic emissions. Int J Audiol 2014; 53: 402-408.

25 Hetu R, Truchon-Gagnon C, Bilodeau SA. Problems of noise in school settings: a review of literature and the results of an exploratory study. $J$ Speech-Lang Path Audiol1990; 14: 31-38.

26 Shield BM, Dockrell JE. The effects of environmental and classroom noise on the academic attainments of primary school children. J Acoust Soc Am 2008; 123: $133-$ 144.

27 Tomlin D, Dillon H, Sharma M, Rance G. The impact of auditory processing and cognitive abilities in children. Ear Hear 2015; 36: 527-542. 
28 Lin A, Northam EA, Werther GA, Cameron FJ. Risk factors for decline in IQ in youth with Type 1 diabetes over the 12 years from diagnosis/illness onset. Diabetes Care 2015; 38: 236-242.

29 Rance G, Ryan MM, Carew P, Corben LA, Yiu E, Tan J et al. Binaural speech processing in individuals with auditory neuropathy. Neuroscience 2012; 226: 227235

30 Rance G, Corben LA, DuBourg E, King A, Delatycki MB. Successful treatment of auditory perceptual disorder in individuals with Friedreich ataxia. Neuroscience 2010; 171: $552-555$.

FIGURE 1 Cochlear function test results for participants with Type 1 diabetes $(\bullet)$ and matched controls $(O)$. (A) Pure-tone sound detection thresholds (mean $\pm 1 \mathrm{SD}$ ). The shaded area represents the normal range for hearing sensitivity. (B) Distortion product otoacoustic emission amplitude (mean $\pm 1 \mathrm{SD}$ ).

FIGURE 2 APHAB Hearing Disability Questionnaire findings for Type 1 diabetes and control cohorts. Values represent the percentage of everyday listening situations in which the child perceived a communication or listening difficulty (mean $\pm 1 \mathrm{SD}$ ).

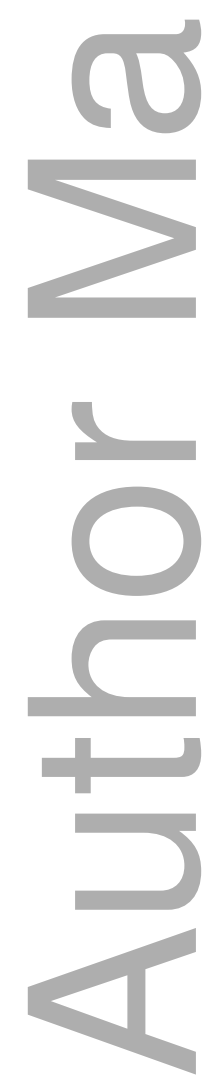


Table 1 Clinical details for participants with Type 1 diabetes

\begin{tabular}{ccccccccc}
\hline Participant & Gender & $\begin{array}{c}\text { Age at } \\
\text { assessment } \\
\text { (years) }\end{array}$ & $\begin{array}{c}\text { Age at } \\
\text { disease } \\
\text { onset } \\
\text { (years) }\end{array}$ & $\begin{array}{c}\text { Disease } \\
\text { duration } \\
\text { (years) }\end{array}$ & $\begin{array}{c}\mathrm{HbA}_{\mathrm{lc}} \\
(\mathrm{mmol} / \mathrm{mol})\end{array}$ & $\begin{array}{c}\mathrm{HbA}_{\mathrm{lc}} \\
(\%)\end{array}$ & Management & $\begin{array}{c}\text { Visual } \\
\text { acuity }\end{array}$ \\
& & & & & & & \\
(LogMAR)
\end{tabular}

LogMAR, Logarithmic minimum angle of resolution (poorer eye); abnormal: $\geq 0.3 \mathrm{~dB}$.

Table 2 ABR findings to $90 \mathrm{dBnHL}$ acoustic click stimuli presented at $33 \mathrm{~Hz}$. Response latencies are expressed in $\mathrm{ms}$ and amplitudes are expressed in $\mu \mathrm{V}$

\begin{tabular}{|c|c|c|c|c|c|c|c|}
\hline Group & $\begin{array}{l}\text { Latency } \\
\text { wave I }\end{array}$ & $\begin{array}{l}\text { Latency } \\
\text { wave III }\end{array}$ & $\begin{array}{l}\text { Latency } \\
\text { wave V }\end{array}$ & $\begin{array}{c}\text { Interpeak } \\
\text { latency I-III }\end{array}$ & $\begin{array}{c}\text { Interpeak } \\
\text { latency III- } \\
\text { V }\end{array}$ & $\begin{array}{c}\text { Interpeak } \\
\text { latency I-V }\end{array}$ & $\begin{array}{c}\text { Amplitude } \\
\text { wave V }\end{array}$ \\
\hline $\begin{array}{c}\text { Type } 1 \\
\text { diabetes }\end{array}$ & $\begin{array}{c}1.42 \\
(0.11)\end{array}$ & $3.68(0.16)$ & $5.58(0.22)$ & $2.26(0.16)$ & $1.90(0.16)$ & $4.16(0.23)$ & $0.50(0.19)$ \\
\hline
\end{tabular}




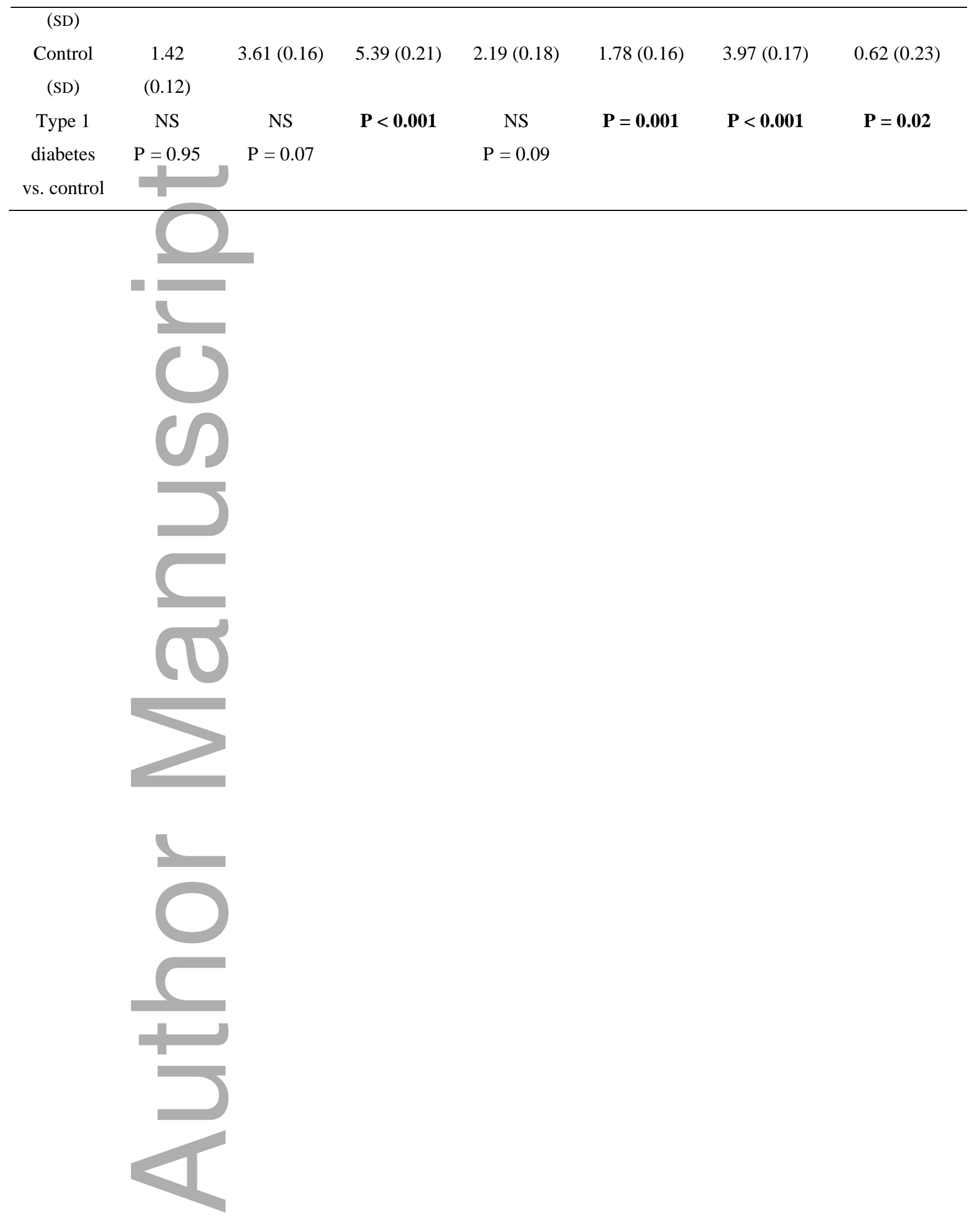


Frequency $(\mathrm{Hz})$

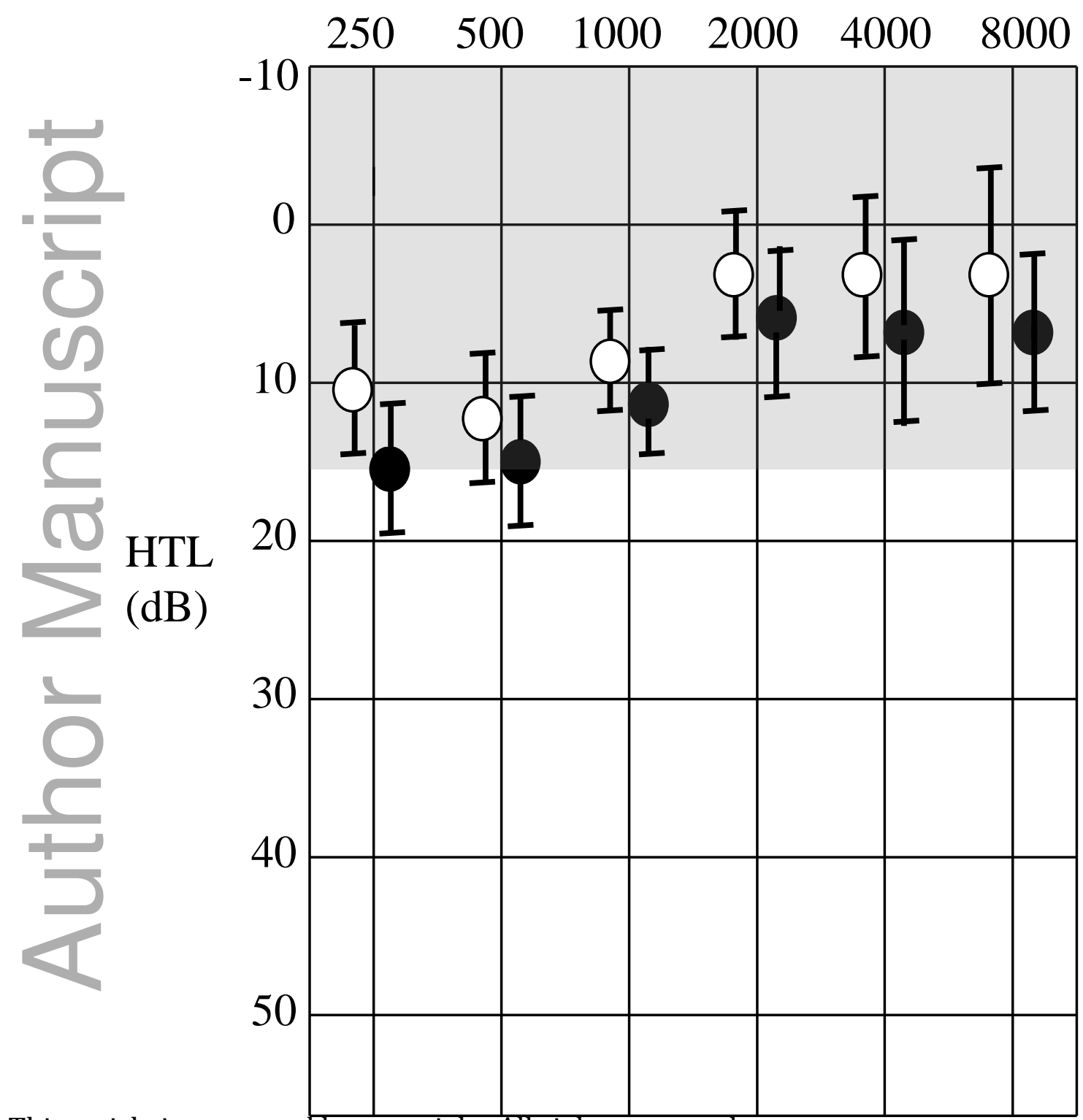

- Diabetes

$\bigcirc$ Control

This article is protected by copyright. All rights reserved 


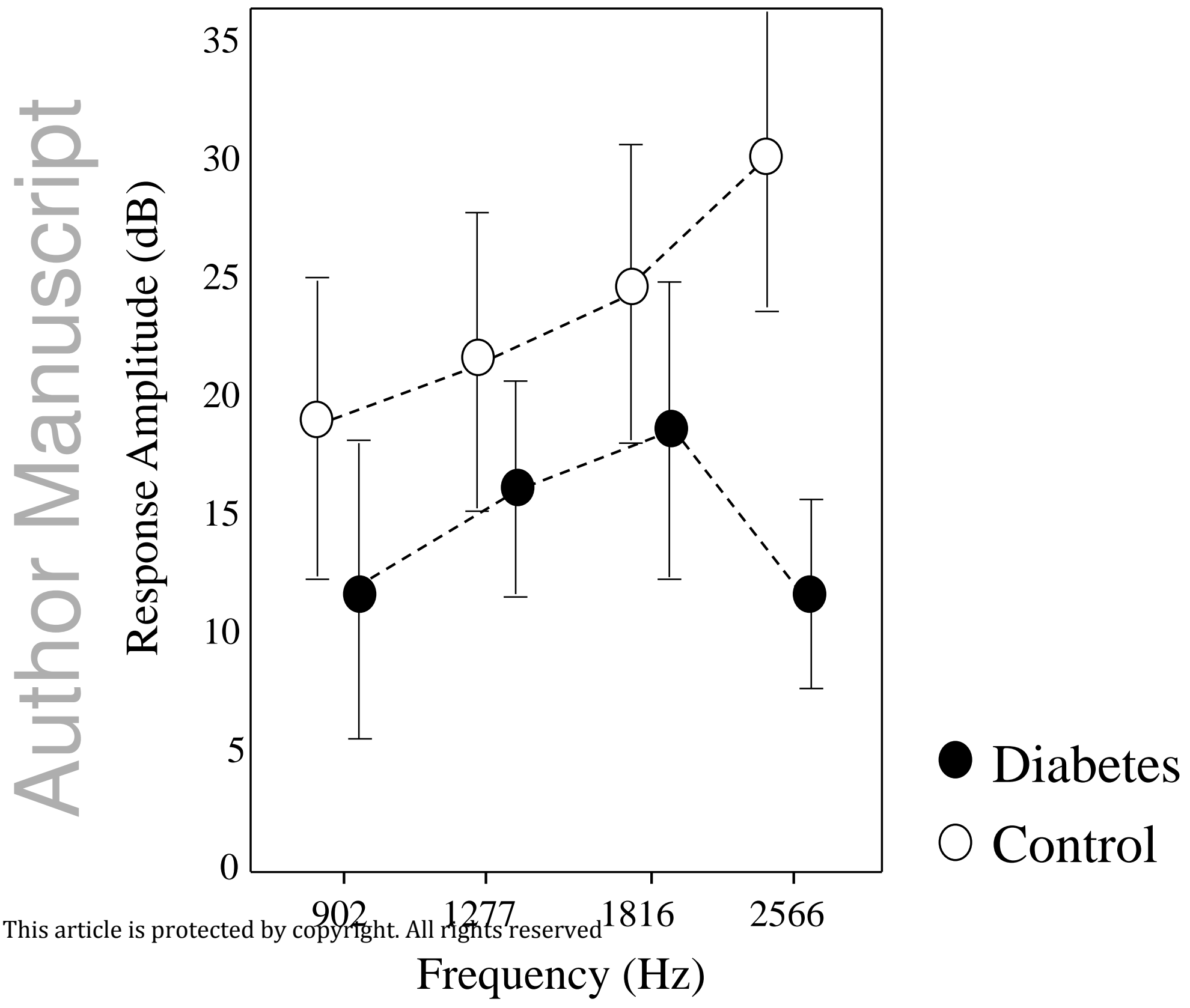




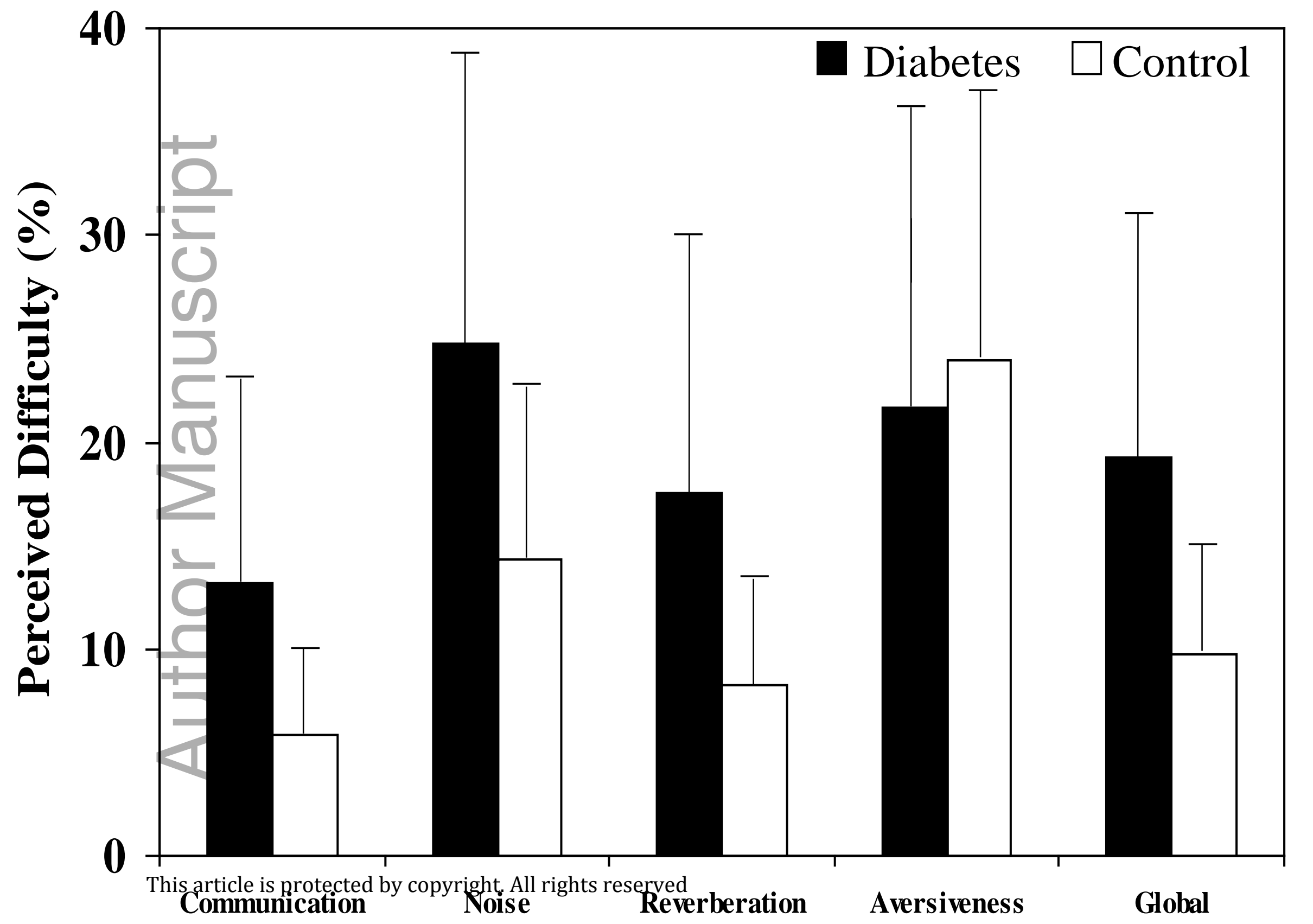




\section{University Library}

\section{- M M I E E R VA A gateway to Melbourne's research publications}

Minerva Access is the Institutional Repository of The University of Melbourne

Author/s:

Rance, G;Chisari, D;Edvall, N;Cameron, F

Title:

Functional hearing deficits in children with Type 1 diabetes

Date:

2016-09-01

Citation:

Rance, G., Chisari, D., Edvall, N. \& Cameron, F. (2016). Functional hearing deficits in children with Type 1 diabetes. DIABETIC MEDICINE, 33 (9), pp.1268-1274. https:// doi.org/10.1111/dme.13086.

Persistent Link:

http://hdl.handle.net/11343/290944 